\title{
Population structure and life history of Hemimysis margalefi (Crustacea: Mysidacea), a 'thermophilic' cave-dwelling species benefiting from the warming of the NW Mediterranean
}

\author{
Christophe Lejeusne* ${ }^{*}$ Pierre Chevaldonné \\ UMR CNRS 6540 'DIMAR', Centre d'Océanologie de Marseille, Station Marine d'Endoume, Rue de la Batterie des Lions, \\ 13007 Marseille, France
}

\begin{abstract}
Dark submarine caves are an extreme and fragmented habitat in which mysids (Crustacea: Mysidacea) of the genus Hemimysis can be found. Hemimysis speluncola has long been the dominant mysid species of the NW Mediterranean caves, but with the recent warming of this region, its congener $H$. margalefi has replaced it. Nothing is known about the biology and ecology of $H$. margalefi and here, we provide the first information about its demographic structure and reproductive biology in a cave recently affected by the species shift. We conducted monthly sampling for $4 \mathrm{yr}$ in the Jarre Island cave, near Marseilles (France), where a population of $H$. margalefi established itself in the late 1990s. Population dynamics were followed by monitoring length-frequency histograms and the influence of temperature on several life-history traits was investigated. H. margalefi reproduces all year round and the brood size depends on female size. Recruitment is discontinuous and occurs when post-nauplioid larvae are 1.3 to $2.0 \mathrm{~mm}$ long. Four annual and overlapping cohorts (about 6 mo long) underline more intensive periods of breeding. Females can produce up to 2 successive cohorts during their life. Whatever the maturity stage, females present larger sizes than males. Seasonal variations of water temperature have a strong influence on different life-history traits of $H$. margalefi, such as mean sizes of the different cohorts, length of intermoult stages and growth rate. Some population dynamics features of $H$. margalefi are a further indication that it is a species with an affinity for warm water, which has recently benefited from the warmer conditions in the NW Mediterranean, colonising new areas and replacing its congener $H$. speluncola in most of its former range.
\end{abstract}

KEY WORDS: Population dynamics · Reproduction - Mysidacea $\cdot$ Hemimysis margalefi $\cdot$ Marine caves $\cdot$ NW Mediterranean · Regional warming

\section{INTRODUCTION}

Dark submarine caves are an extreme and fragmented habitat of the littoral zone with environmental conditions characterised by a complete absence of light, marked oligotrophy and reduced water circulation (Harmelin et al. 1985, Fichez 1990a, 1991). Such conditions make marine caves rather similar to the deep sea and some bathyal species are known to have successfully colonised caves (Harmelin et al. 1985, Hart et al. 1985, Vacelet et al. 1994, Vacelet \& BouryEsnault 1996). The environmental contrast between caves and the rest of the littoral zone, therefore, makes it very interesting to study evolutionary processes in such isolated habitat patches. However, dark marine cave fauna is not restricted to species of deep-sea affinities. Faunistic composition varies with biogeographical regions, but is nevertheless strongly deter- 
mined by those particular environmental conditions. The decrease in light and food availability, from the entrance to the interior of the caves, has a major influence on the communities: decreased abundances and densities, and changes in composition (Harmelin et al. 1985, Fichez 1990a, 1991). The main sessile invertebrate taxa occurring in dark caves are most often sponges, bryozoans and serpulid polychaetes (Harmelin et al. 1985, Vacelet et al. 1994, Vacelet \& Boury-Esnault 1995, Harmelin 1997). Mobile fauna is mainly represented by fishes and crustaceans, including mysids (Crustacea: Mysidacea), which are a rather common taxonomic group in caves and associated cryptic or 'crevicular' habitats (sensu Hart et al. 1985). Mysids are characterised by the development of their young in a marsupium, which means that dispersal can only be achieved by adults or juveniles (Mauchline 1980). How brooding species such as mysids manage to maintain connections between cave populations, when a direct consequence of this life-history trait is that gene flow between populations is expected to be reduced, is particularly puzzling. A prerequisite for the understanding of the relationship between cave habitat patchiness and cave invertebrate life-history traits is to document the actual ecology, reproductive biology and demographic population structures of model taxa.

The 2 mysid species Hemimysis speluncola and $H$. margalefi are endemic of NW Mediterranean caves. Both species are strongly sciaphilic and may live in sympatry only in the darkest parts of the caves where they usually form swarms (Ledoyer 1963, Harmelin et al. 1985, Alcaraz et al. 1986, Passelaigue \& Bourdillon 1986, Chevaldonné \& Lejeusne 2003). H. speluncola is a high-density swarming species whose populations present spatial heterogeneity and seasonal variations (Ledoyer 1989, Ribes et al. 1996), while $H$. margalefi forms swarms of comparatively lower density (Chevaldonné \& Lejeusne 2003).

Hemimysis speluncola was the focus of many studies from its discovery (Ledoyer 1963) to the 1980s (see Chevaldonné \& Lejeusne 2003 for a literature survey). In contrast, from its original description (Alcaraz et al. 1986) to the beginning of this project, there have been very few studies published on the biology and ecology of $H$. margalefi, which has been treated in a comparative taxonomic study of the genus Hemimysis (Ledoyer 1989) and listed in a few recent faunistic surveys (Wittmann 2001, Harmelin et al. 2003). Yet, the importance of $H$. margalefi in the cave ecosystem is not negligible since it has now replaced its congener $H$. speluncola as the dominant cave-dwelling mysid species in most NW Mediterranean caves (Chevaldonné \& Lejeusne 2003). Causes of this species shift have been shown to be related to the more thermophilic character- istics of $H$. margalefi that, in the context of the warming of Mediterranean waters, allowed it to successfully outcompete $H$. speluncola, as has been documented for the Marseilles area (France), after 1999. To date, H. margalefi has been reported from the Balearic Islands, the continental coast of Europe from Marseilles to Naples, Corsica, Malta and the Croatian coast of the Adriatic Sea (Chevaldonné \& Lejeusne 2003). It occurs in most of the caves visited by the authors, as long as they are dark enough and protected from wave action and currents. Before the 1999 species shift, $H$. margalefi had been observed in relatively small numbers in some caves of the Marseilles area (Ledoyer 1989), while today, they are the only mysid species found in dark marine caves of the NW Mediterranean, with very few exceptions (Chevaldonné \& Lejeusne 2003).

The Jarre Island cave, located in the Marseilles area, harbours an important population of Hemimysis margalefi, that is also the best studied of this species. It has been the focus of the present study to document its population dynamics and reproductive biology over several years, thus providing background for future population genetic studies. Considering the success of $H$. margalefi in the context of regional warming, particular attention has been focused on the influence of temperature on population parameters.

\section{MATERIALS AND METHODS}

Study site and sampling. The large cave of Jarre Island $\left(43.2^{\circ} \mathrm{N}, 5.4^{\circ} \mathrm{E}, 15\right.$ to $17 \mathrm{~m}$ depth) is located in the Riou archipelago near Marseilles (France) (Fig. 1). It is ca. $130 \mathrm{~m}$ long and presents totally dark parts where mysids were collected (ca. $70 \mathrm{~m}$ from the entrance). Samples were collected on a monthly basis (depending on weather and diving conditions) between January 2000 and November 2003 by SCUBA using diver-operated, specially-designed, suction bottles (squirt bottles fitted with a nozzle, 2 valves and a $400 \mu \mathrm{m}$ mesh-size filter).

Demographic and size structure. Collected mysids were identified in vivo under a dissecting microscope and total length (TL) was measured from the tip of the rostrum to the posterior extremity of the telson. Individuals were ascribed to 1 of the following 6 demographic categories, on the basis of their sexual characteristics, following in great part Mauchline's classification (1980): (1) juveniles: secondary sexual characteristics absent, (2) immature males: penes rudimentary or absent, secondary sexual characteristics (hypertrophy of 4th pleopods) developing, (3) mature males: penes and 4th pleopods fully developed, (4) immature females: rudimentary marsupium present, (5) mature females: secondary sexual characteris- 


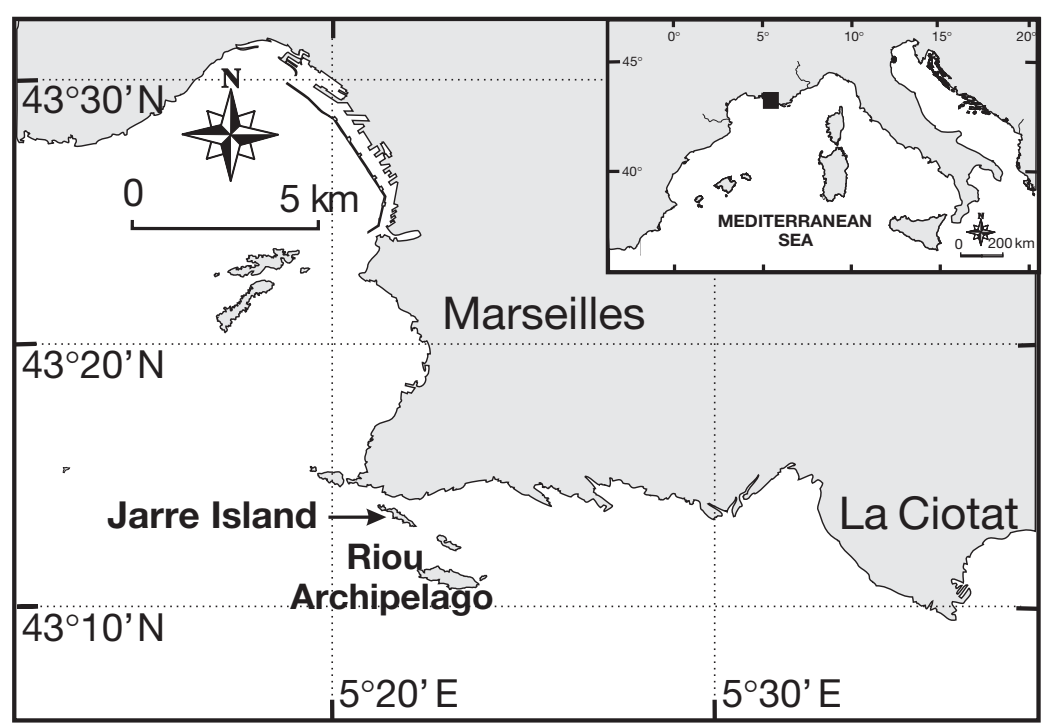

Fig. 1. Location of the Jarre Island cave in the Marseilles area (France) and in the north-west Mediterranean (black square in the box)

2002 (11 January 2000 to 31 December 2002). In 2003 (January 20 to November 26), the Jarre cave was equipped with its own temperature recorder where mysids can be found during the day. Seamon $^{\circledR}$ mini temperature loggers (Hugrún) were used with recording intervals of $3 \mathrm{~h}$.

Description of marsupial content. The number of embryos or larvae per incubating female was measured, and embryonic and larval development was classified according to the 3 main stages of development described by Wittmann (1981): (1) embryonic stage (no distinguished appendages), (2) nauplioid stage (thoracic appendages in development) and (3) post-nauplioid stage (thoracic appendages fully developed and distinct stalked eyes). Maximum diameter was measured for embryos and total length for larvae (nauplioid and post-nauplioid stages). The term

tics fully developed with empty marsupium, and (6) incubating females: mature females with young in the marsupium.

Each demographic category was monitored over the sampling period and the sex ratio (number of mature males:number of mature and incubating females) was followed over the whole sampling period. In order to more accurately determine the size at sexual maturity in both sexes, the proportion of identified mature individuals (including incubating females for females) by size-class was fitted to a logistic equation:

$$
P_{i}=1 /\left[1-\exp \left(a_{i} \times \mathrm{TL}_{i}+b_{i}\right)\right]
$$

where $P_{i}$ is the predicted proportion of mature females $\left(P_{i}=P_{\mathrm{f}}\right)$ or males $\left(P_{i}=P_{\mathrm{m}}\right), a_{i}$ and $b_{i}$ the estimated coefficients of the logistic equation, and $\mathrm{TL}_{i}$ the total length of females $\left(\mathrm{TL}_{\mathrm{f}}\right)$ or males $\left(\mathrm{TL}_{\mathrm{m}}\right)$. Estimation of parameters was made by correlation analysis of variables $P$ and TL in the Statistica ${ }^{\circledR} 5.1$ package (StatSoft 1998). Size at sexual maturity $\mathrm{TL}_{i(50)}$, corresponding to a proportion of 0.5 sexually mature females $\mathrm{TL}_{\mathrm{f}(50)}$ or males $\mathrm{TL}_{\mathrm{m}(50)}$, was estimated as the opposite of the ratio of the coefficients, such as $\mathrm{TL}_{i(50)}=-\left(b_{i} / a_{i}\right)$, by substituting $P_{i}=0.5$ in the equation (Oh \& Hartnoll 2004).

Temperature recordings. In order to study the influence of seawater temperature on the biology of Hemimysis margalefi, we obtained 2 types of water temperature time-series. At the beginning of this survey, a temperature recording station existed on a nearby island of the Riou archipelago, located only a couple of kilometres from Jarre cave (depth: $11 \mathrm{~m}$; station set-up by J. G. Harmelin), which we used for the years 2000 to 'young' is used to refer to the 3 categories of intra-marsupial individuals. The relationship between brood size and incubating female size was studied using Pearson's correlation coefficient.

Population dynamics. Whenever possible, a subsample of 100 individuals of Hemimysis margalefi was used to establish length-frequency histograms with a $0.25 \mathrm{~mm}$ class-size interval in order to respect Sturge \& Yule's rules (Scherrer 1984). The representativeness of subsamples had been statistically tested in a previous preliminary study (Lejeusne 2002). Normality of the distributions was tested with a Wilks-Shapiro test (W-test) using the Statistica ${ }^{\circledR} 5.1$ package (StatSoft 1998). Histograms were then smoothed with a moving average to rule out non-significant peaks (Frontier \& Picho-Viale 1991) and a modal decomposition of the distributions was made according to Bhattacharya's method (1967), using MIX 2.3 software (Macdonald \& Green 1988). For each distribution, the number of modes, their means, their standard deviation and the proportions in which they contributed to the shape of the distribution were computed. They were then used for the temporal monitoring of the different modes of the distributions, which allowed the determination of the number and the duration of the different cohorts of $H$. margalefi (defined as a group of individuals of the same age recruited into the population at the same time). From the monitoring of the size distribution modes, it was possible to obtain a rough estimate of the growth rate of this species: regression lines were fitted to the evolution of each mode through time and growth rate could be estimated as the average slope. Consid- 
ering the nature and the frequency of our data, this very simple estimation method seemed most appropriate at this stage, pending confirmation by an experimental study on individual, reared $H$. margalefi.

\section{RESULTS}

Among the 3778 individuals examined for this study in Jarre cave, Hemimysis margalefi was the only Hemimysis species found. A few individuals of Harmelinella mariannae, another more distantly related cave mysid, were sometimes collected $(<20$ ind. over the sampling period) but no morphological ambiguity exists to segregate the 2 species. Occasional sampling from 1998, and the monthly sampling conducted between January 2000 and November 2003, revealed important, yet unexplained, population fluctuations (pers. obs.).

\section{Demographic structure}

All 6 demographic categories of Hemimysis margalefi were present throughout the sampling period but the percentage of the different categories in the population varied markedly. However, no general pattern could be deduced from these variations. The permanent occurrence of incubating females is characteristic of a species with continuous reproduction all year round.

The sex ratio (number of mature males:number of mature and incubating females), calculated over the whole sampling period, is 1.15 and shows some variations (Fig. 2). However, it does not differ significantly from a balanced sex ratio (chi-square test, $\mathrm{df}=37, \chi^{2}=$ 13.08), nor do the different annual sex ratios (Table 1).

As shown in Fig. 3 and Table 2, females are larger compared to males in most of the samples. These sexual differences are statistically significant when com-

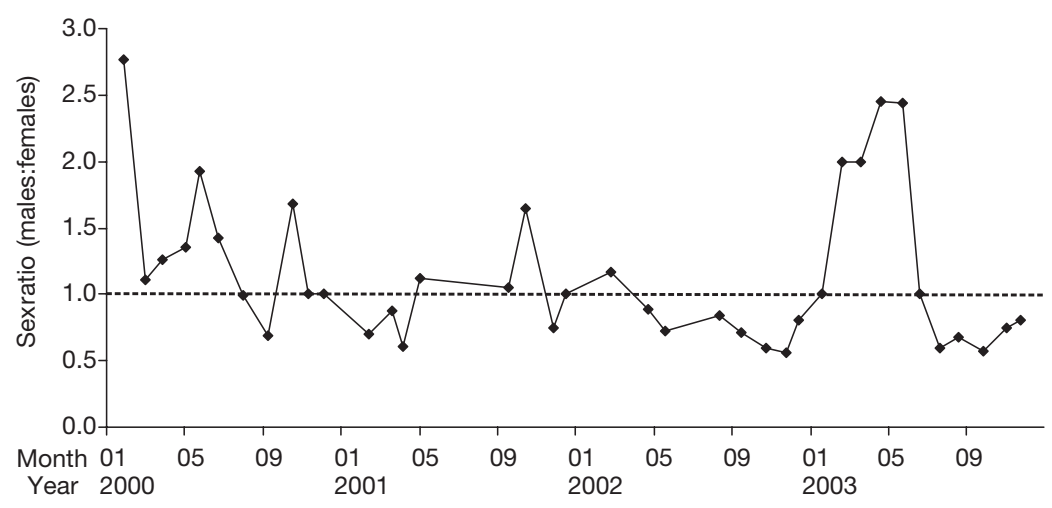

Fig. 2. Hemimysis margalefi. Temporal variations in the sex ratio (number of mature males:number of mature and incubating females). Horizontal line corresponds to a balanced sex ratio
Table 1. Hemimysis margalefi. Sex ratio (number of mature males:number of incubating and mature females) and $\chi^{2}$-test of no difference with equilibrate sex ratio $\left(\chi^{2}\right.$ value; $d f$ : degrees of freedom)

\begin{tabular}{|lrrr|}
\hline & Sex ratio & $\chi^{2}$ & df \\
\hline 2000 & 1.29 & 5.06 & 10 \\
2001 & 0.95 & 0.66 & 7 \\
2002 & 0.78 & 0.62 & 7 \\
2003 & 0.99 & 6.75 & 10 \\
All samples & 1.15 & 13.08 & 37 \\
\hline
\end{tabular}

Table 2. Hemimysis margalefi. Size of the different demographic categories. $n$ : sample size; $\mu \pm$ SE: mean total length $\pm \mathrm{SE}(\mathrm{mm})$; Min: minimum total length $(\mathrm{mm})$; Max: maximum total length $(\mathrm{mm})$; 10th: 10th percentile $(\mathrm{mm})$; 90th: 90th percentile (mm)

\begin{tabular}{|lrccccc|}
\hline & $\mathrm{n}$ & $\mu \pm \mathrm{SE}$ & Min & Max & 10th & 90th \\
\hline Juveniles & 1124 & $2.6 \pm 0.01$ & 1.3 & 3.6 & 2.0 & 3.2 \\
Immature o & 486 & $3.4 \pm 0.02$ & 2.4 & 5.2 & 2.9 & 4.0 \\
Immature o & 267 & $3.7 \pm 0.02$ & 2.1 & 4.8 & 3.3 & 4.2 \\
Mature ơ & 954 & $4.6 \pm 0.02$ & 2.6 & 6.5 & 3.9 & 5.5 \\
Mature o & 472 & $4.7 \pm 0.02$ & 3.5 & 7.1 & 4.0 & 5.7 \\
Incubating o & 475 & $5.0 \pm 0.02$ & 3.1 & 7.0 & 4.3 & 5.9 \\
Total & 3778 & $3.9 \pm 0.02$ & & & & \\
\hline
\end{tabular}

paring mature males and mature females (Wilcoxon paired-samples test, $\mathrm{n}=38, \mathrm{z}=2.46, \mathrm{p}=0.014$ ), and highly significant when comparing either mature males and incubating females $(\mathrm{n}=36, \mathrm{z}=5.23, \mathrm{p}<$ $0.001)$ or immature males and immature females $(\mathrm{n}=$ $38, \mathrm{z}=4.73, \mathrm{p}<0.001)$. The size at onset of sexual maturity ( $>5 \%$ mature) is 3 to $3.5 \mathrm{~mm}$ for males and 3 to $3.25 \mathrm{~mm}$ for females (Table 3 ). The proportion of mature individuals was fitted to total length by a logistic function, such as: $P_{\mathrm{m}}=1 /\left[1-\exp \left(4.692 \times \mathrm{TL}_{\mathrm{m}}-\right.\right.$ 18.148)] $\left(\mathrm{r}^{2}=0.9945, \mathrm{p}<0.001\right)$ for mature males and $P_{\mathrm{f}}=1 /\left[1-\exp \left(5.464 \times \mathrm{TL}_{\mathrm{f}}-23.709\right)\right]\left(\mathrm{r}^{2}=0.9980, \mathrm{p}<\right.$ 0.001) for mature females (including incubating females). The resulting estimated size for $50 \%$ sexual maturity is $\mathrm{TL}_{\mathrm{m}(50)}=3.87$ $\mathrm{mm}$ for males and $\mathrm{TL}_{\mathrm{f}(50)}=4.34 \mathrm{~mm}$ for females.

\section{Relationship between mean size and water temperature}

Mean sizes of the different demographic categories show marked seasonal variations with a maximum around early spring and a minimum around early autumn (Fig. 3). These variations exist in all the demographic categories but they seem to have less 

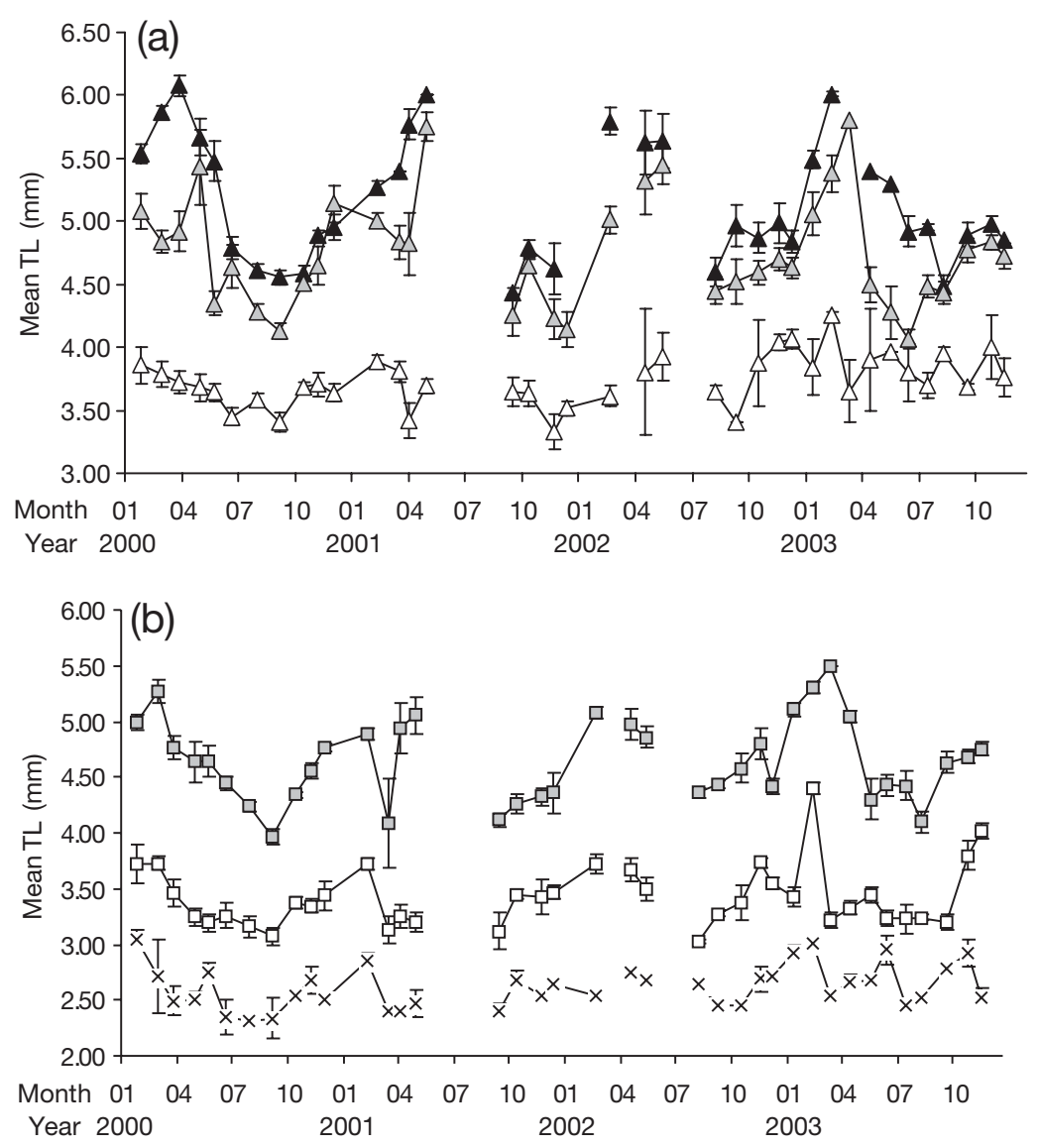

Fig. 3. Hemimysis margalefi. Total length (mean TL) variations of (a) females (triangles) and (b) males (squares) and juveniles (crosses). White symbols: immature individuals; grey symbols: mature individuals; black triangles: incubating females

amplitude in the youngest, least mature categories. Temperature data from Riou Island (2000 to 2002) and from Jarre cave (2003) were used to study the influence of seasonal variations of temperature on life-history traits of Hemimysis margalefi. The mean sizes of the different samples present a significant negative correlation over the sampling period (Spearman's rank correlation coefficient, $\mathrm{R}=-0.23, \mathrm{n}=37, \mathrm{p}=0.17$ ) with seasonal temperature variations. Thus, in March to April, water temperature is rather stable but is also the coldest of the year $\left(13.77 \pm 0.02^{\circ} \mathrm{C}_{i}\right.$ mean $\left.\pm \mathrm{SE}\right)$ and mean sizes are maximal. In September, water temperature is high $\left(18.48 \pm 0.08^{\circ} \mathrm{C}\right)$ but with strong variations over short periods of a few days (Fig. 4a).

\section{Characteristics of marsupial content}

As shown in Table 4, as larvae develop in the marsupium, the brood size of incubating females decreases. Furthermore, a significant positive linear correlation exists between the logarithm of the number of young $(Y)$ present in the marsupium and the logarithm of the incubating female mean size $(X)$, as $\log Y=0.1042 \log X+0.6493(\mathrm{R}=$ 0.8299, $\mathrm{p}<0.01$ ). Consequently, brood size presents seasonal variations that correspond to the seasonal female mean size variations relative to temperature fluctuations (Spearman's rank correlation coefficient, $\mathrm{R}=-0.38, \mathrm{n}=$ $29, p=0.03)$. The size of hatched larvae can be assumed to range between that of the biggest intra-marsupial post-nauplioid larvae (90th percentile $=1.7 \mathrm{~mm}$; maximum $=2.0 \mathrm{~mm}$ ) and that of the smallest juveniles caught in the cave population $\left(\right.$ minimum $=1.3 \mathrm{~mm} ; 10^{\text {th }}$ percentile $=2.0 \mathrm{~mm}$ ). The size range 1.3 to $2.0 \mathrm{~mm}$ thus corresponds to the size at which larval development is completed, and juveniles hatch and begin to be recruited into the free swimming population.

\section{Modal monitoring}

Over the 38 size distributions studied, 37 differ significantly from normality (Wilks-Shapiro [W-test], p < 0.05). Battacharya's method indicates plurimodality of all the length-frequency distributions with the presence of 2 or 3 modes in each distribution (Fig. 5). The distributions show an overlap of cohorts and a variable intensity in the recruitment. Recruitment is considered here as the expulsion of larvae having completed development (i.e. becoming juveniles) from the marsupium and their arrival in the free-swimming population.

The modal monitoring of the population of Hemimysis margalefi allowed the discrimination of 4 cohorts produced per year. We name these 4 cohorts according to the main season of their recruitment. Individuals of the spring cohort appear mainly between March (2000, 2002 and 2003) and the beginning of May (2001). This cohort disappears in October. The following summer cohort appears around the end of June and lasts until December. The autumn cohort is staggered over the period between October and the beginning of April. In the beginning of December (November in 2000), mature individuals produce the winter cohort which ends in June.

The life span of each cohort varies from year to year but over the 4 yr surveyed here, it seems that the sum- 
Table 3. Hemimysis margalefi. Total number of individuals in both sexes, and in mature females (including incubating females) and males arranged by class intervals, and corresponding proportions

\begin{tabular}{|lrrrrrr|}
\hline $\begin{array}{l}\text { Mid-point } \\
(\mathrm{mm})\end{array}$ & $\begin{array}{r}\text { Total } \\
\text { no. of } \\
\text { males }\end{array}$ & $\begin{array}{c}\text { No. of } \\
\text { mature } \\
\text { males }\end{array}$ & $\begin{array}{c}\text { Proportion } \\
\text { of mature } \\
\text { males }\end{array}$ & $\begin{array}{c}\text { Total } \\
\text { no. of } \\
\text { females }\end{array}$ & $\begin{array}{c}\text { No. of } \\
\text { mature } \\
\text { females }\end{array}$ & $\begin{array}{c}\text { Proportion } \\
\text { of mature } \\
\text { females }\end{array}$ \\
\hline 2.375 & 9 & 0 & 0.000 & & & \\
2.625 & 24 & 3 & 0.125 & & & \\
2.875 & 78 & 1 & 0.013 & 7 & 0 & 0.000 \\
3.125 & 111 & 5 & 0.045 & 20 & 1 & 0.050 \\
3.375 & 197 & 28 & 0.142 & 119 & 6 & 0.050 \\
3.625 & 130 & 49 & 0.377 & 114 & 9 & 0.079 \\
3.875 & 245 & 155 & 0.633 & 158 & 67 & 0.424 \\
4.125 & 186 & 162 & 0.871 & 147 & 101 & 0.687 \\
4.375 & 310 & 297 & 0.958 & 269 & 239 & 0.888 \\
4.625 & 166 & 163 & 0.982 & 185 & 185 & 1.000 \\
4.875 & 197 & 197 & 1.000 & 227 & 227 & 1.000 \\
5.125 & 197 & 197 & 1.000 & 122 & 122 & 1.000 \\
5.375 & 83 & 83 & 1.000 & 109 & 109 & 1.000 \\
5.625 & 87 & 87 & 1.000 & 48 & 48 & 1.000 \\
5.875 & 48 & 48 & 1.000 & 82 & 82 & 1.000 \\
6.125 & 49 & 49 & 1.000 & 33 & 33 & 1.000 \\
6.375 & 6 & 6 & 1.000 & 23 & 23 & 1.000 \\
6.625 & 7 & 7 & 1.000 & 6 & 6 & 1.000 \\
6.875 & & & & 2 & 2 & 1.000 \\
7.125 & & & & 1 & 1 & 1.000 \\
\hline
\end{tabular}
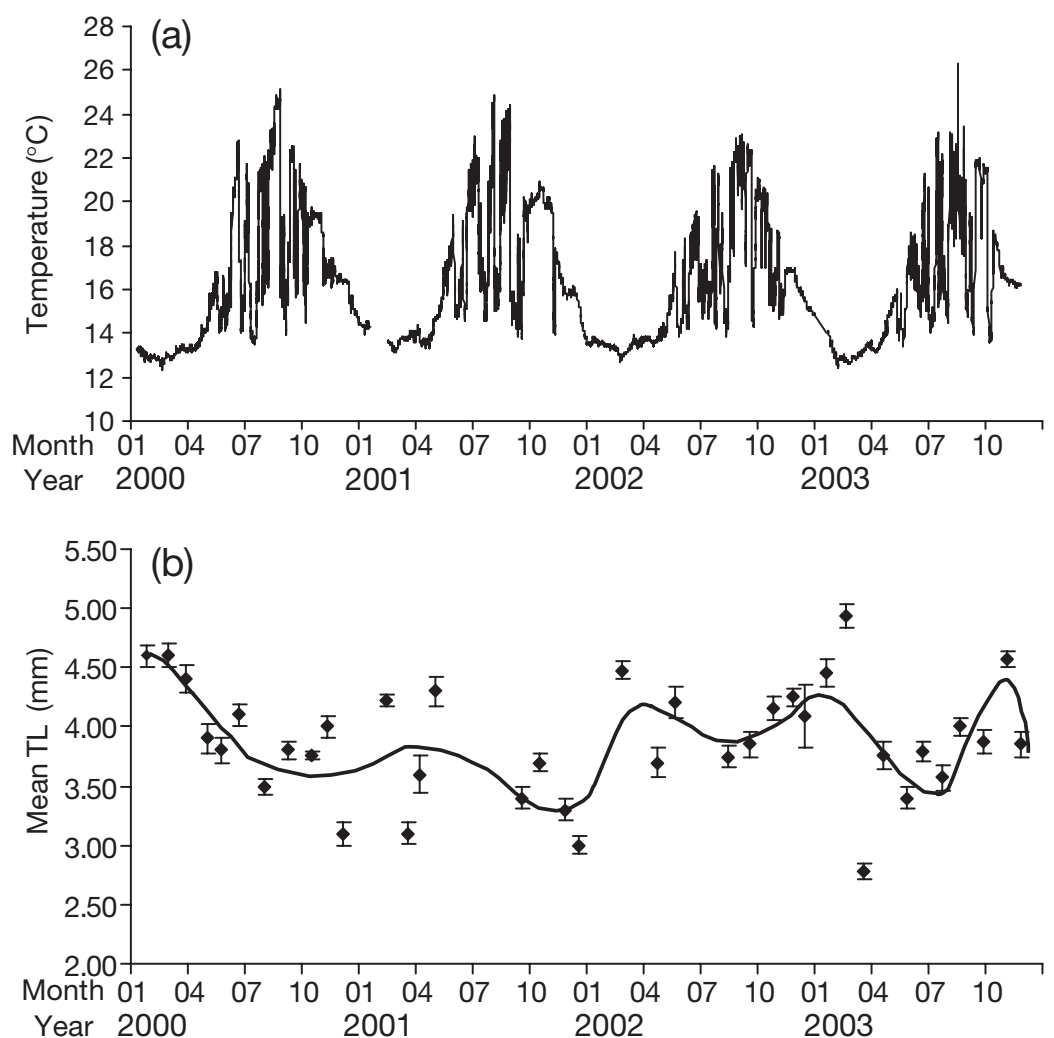

Fig. 4. Comparison of (a) water temperatures in the Riou archipelago (2000 to 2003) and (b) total length (mean TL) of Hemimysis margalefi in the Jarre cave population $( \pm \mathrm{SE})$. Bold line in (b) corresponds to a polynomial regression of mean TL values mer and autumn cohorts are the shortest (5 to $6 \mathrm{mo}$ ). The spring cohort lasts ca. 6 mo and the winter cohort is the longest (6 to $7 \mathrm{mo}$ ). As many distributions display more than 2 modes, we suggest that some mature individuals (i.e. from the third, oldest cohort of a distribution) may have participated in producing 2 successive cohorts (first and second cohorts of the same distribution). Based on the monitoring of the modes over our sampling period, a first estimate of Hemimysis margalefi's growth rate was computed to be ca. $0.02 \mathrm{~mm} \mathrm{~d}^{-1}$.

\section{DISCUSSION}

\section{Demographic characteristics of sexual categories}

The maximum mean size of freeswimming forms of Hemimysis margalefi is obtained for incubating females $(5.0 \mathrm{~mm}$; Table 2). This size is significantly smaller than that of corresponding forms of $H$. speluncola, reported between 6 and $8 \mathrm{~mm}$ depending on the season (Ledoyer 1963, 1989, Gaudy \& Guérin 1979). Females of both species present a much higher mean size than males (Ledoyer 1989), but in the particular case of $H$. margalefi, the difference is significant whatever the season or the degree of maturity considered (immature or mature). Mauchline (1980) indicates that, in general, female mysids grow larger than males, which is due to more frequent moults in males combined with a slower growth rate. This differential growth implies that male sexual characteristics are recognised at smaller sizes than females. Our results are in good agreement with this general pattern since mature males present a size (corresponding to $50 \%$ sexually mature individuals) of 3.87 versus $4.34 \mathrm{~mm}$ for mature females at sexual maturity.

Consequently, in order to minimise the effects of a possible earlier identification of males versus females by the observer, only fully mature individuals were used to estimate the sex ratio of 
Table 4. Hemimysis margalefi. Brood size (number of individuals per marsupium) and size (maximum diameter for embryos and total length for larvae) of the successive intra-marsupial stages. $\mathrm{n}$ : total number of young examined; $\mu \pm \mathrm{SE}$ : mean \pm SE; Min: minimum; Max: maximum; E: embryos; $\mathrm{L}_{\mathrm{I}}$ : nauplioid larvae; $\mathrm{L}_{\mathrm{II}}$ : post-nauplioid larvae

\begin{tabular}{|cccccc|}
\hline & & $\mathrm{E}$ & $\mathrm{L}_{\mathrm{I}}$ & $\mathrm{L}_{\mathrm{II}}$ & Total \\
\hline Brood size & $\mathrm{n}$ & 114 & 185 & 113 & 412 \\
& $\mu \pm \mathrm{SE}$ & $6.41 \pm 0.25$ & $6.15 \pm 0.23$ & $5.20 \pm 0.24$ & $5.95 \pm 0.14$ \\
& $\mathrm{Max}$ & 15 & 18 & 13 & 18 \\
Size $(\mathrm{mm})$ & $\mu \pm \mathrm{SE}$ & $0.48 \pm 0.01$ & $1.03 \pm 0.01$ & $1.50 \pm 0.02$ & $0.98 \pm 0.02$ \\
& $\mathrm{Min}$ & 0.3 & 0.8 & 1.0 & 0.3 \\
& $\mathrm{Max}$ & 0.9 & 1.6 & 2.0 & 2.0 \\
& & & & & \\
\hline
\end{tabular}

Hemimysis margalefi (ratio of mature males:mature and incubating females). This sex ratio shows variations between samples and between seasons that no clear pattern (such as a correlation with temperature fluctuations) appears to explain. Several hypotheses could explain these fluctuations: (1) male or female mortality following copulation or breeding could lead to the dominance of one sex over the other, or (2) males and females may also have a different life duration. However, both hypotheses require fluctuations in sex
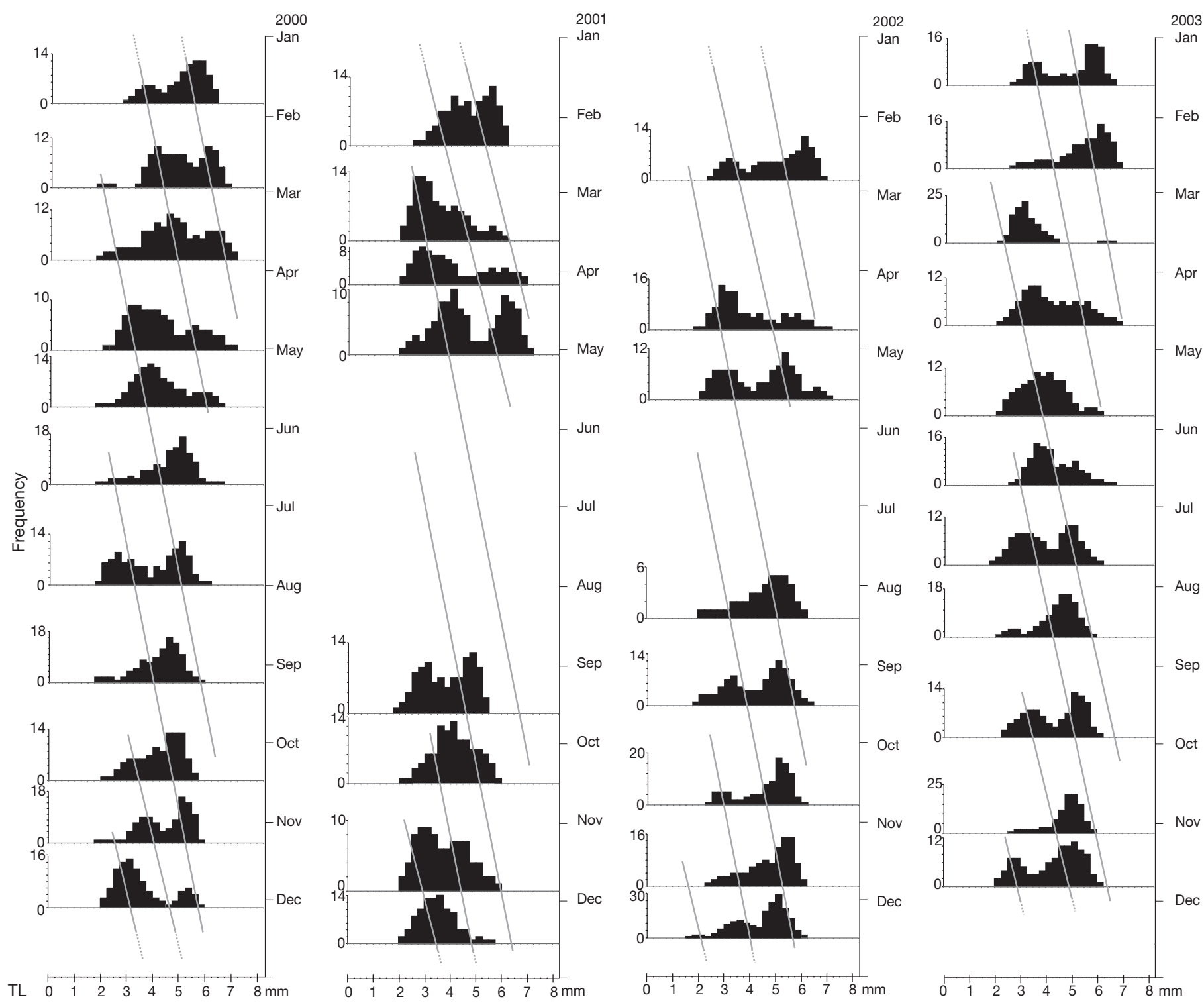

Fig. 5. Hemimysis margalefi. Length-frequency histograms of individuals collected from 2000 to 2003. Each grey line represents the temporal monitoring of cohorts. Note the scale-change of the vertical axis of the different distributions 
ratio to have a repeated generation-based pattern that does not appear in the $4 \mathrm{yr}$ of our data set. Another explanation (3) could be a recognition of mature males by the observer at a smaller size than for females, although we only used fully mature individuals in this calculation (see above). In addition, under this assumption, the sex ratio should always have been biased in favour of males and the overall sex ratio calculated over a year or over the present sampling period should be higher than 1 . Here, the sex ratio calculated over the whole sampling period is not statistically different from the equilibrate sex ratio, so this hypothesis is unlikely. Finally, (4) it is possible that minor undetected patterns of sexual segregation within the swarm when sampling $H$. margalefi swarms might have driven us to collect unbalanced proportions of both sexes. Many mysid species, including $H$. anomala, have already been reported to present fluctuations in sex ratio as documented here for $H$. margalefi, without any obvious reasons to explain them (Mauchline 1980, Ketelaars et al. 1999). There are no data in the literature on the sex ratio of $H$. speluncola, but preliminary observations indicate the same pattern as for $H$. margalefi: very large fluctuations of the ratio in individual samples, but a balanced overall ratio of 1 (unpubl. data).

Incubating females of Hemimysis margalefi, just as all other demographic categories, were present in each sample whatever the year and the period considered, which indicates that the species reproduces year round. Such a reproductive pattern is common in brooding marine invertebrates of temperate seas (Giese 1959). Female $H$. margalefi present a mean brood size of 5.95 young per female and we noted that brood size is strongly dependent on the size of incubating females, a common feature of peracarid crustaceans such as mysids (Mauchline 1973, 1980, Wittmann 1984, Ketelaars et al. 1999). This relationship is a linear positive correlation between the logarithm of incubating female size and the logarithm of the brood size. The duration of the incubation in the marsupium and the duration of the different development stages are variable among mysid species and also depend on environmental factors. A duration of marsupial development between 11 and $31 \mathrm{~d}$ depending on temperature has been reported for the closely related species H. speluncola (Macquart-Moulin \& Patriti 1966, Gaudy \& Guérin 1979). We could not individually monitor incubating females of $H$. margalefi in the present study, but we noted that some mortality occurs during marsupial development (19\% between the embryonic stage and the post-nauplioid stage). Such mortality has commonly been reported in mysids, but with a lower average rate of $10 \%$ (Mauchline 1973, Wittmann 1984). The higher value observed in our study is most certainly overestimated due to the likely expulsion of some young from the marsupium upon capture. For the same reason, our mean brood size value is probably underestimated. An experimental determination of these life-history traits remains to be obtained for H. margalefi. The development of young into a brood pouch allows their direct recruitment at the juvenile stage in the local population. In the $H$. margalefi Jarre population, this recruitment occurs when postnauplioid larvae are 1.3 to $2.0 \mathrm{~mm}$ long, which is identical to what was reported for $H$. lamornae (Mauchline 1980). Newly recruited juveniles are sometimes missing from the histograms in Fig. 5. This is probably due to some degree of spatial segregation between the different size classes of the cave population. This makes adequate sampling of all categories difficult on some occasions.

\section{Population structure and dynamics}

Although reproduction occurs all year round, recruitment of Hemimysis margalefi is discontinuous. This is also the case in the related species $H$. speluncola (Gaudy \& Guérin 1979) and H. lamornae (Mauchline 1971). The modal monitoring of length-frequency histograms of $H$. margalefi from 2000 to 2003 reveals that 4 cohorts are produced per year, with their recruitment centred around April, July, October and December. The occurrence of distinct cohorts in a species reproducing all year round implies either the existence of more intensive periods of reproduction followed by intensive periods of breeding or more intensive periods of recruitment. Variability in recruitment intensities is here directly dependent on the intensity of breeding, since there is no free larval life. Females from one cohort breed the next cohort, but we noted that some females can participate in breeding 2 successive cohorts during their life. Breeding different cohorts and continuous reproduction is characteristic of mysid species producing at least 3 cohorts per year (Mauchline 1980). The exact life span of each cohort is difficult to determine in such species because the resulting population structure is an overlap of several age groups (Wittmann 1984, San Vicente \& Sorbe 1993). From the structures obtained here, we could however, determine that the duration of each cohort of $\mathrm{H}$. margalefi lasts for ca. 6 mo. Summer and autumn cohorts that occur during the warmest period are the shortest, and the winter cohort, present during the coldest period, is the longest. This could be explained by a different duration of intermoult stages: warmer temperatures in summer and autumn likely result in shorter intermoult duration, whereas colder temperatures increase the intermoult period. 


\section{Influence of temperature}

Environmental conditions can play an important role in the timing of reproduction. In many poikilotherm species, particularly crustaceans, temperature is considered one of the main factors conditioning the occurrence and efficiency of reproduction and recruitment. In some areas of the Mediterranean Sea, several mysid species stop breeding during winter due to the strong seasonal variation of water temperatures (Wittmann 1984). The Jarre Island population of Hemimysis margalefi, near Marseilles, is located in one of the northernmost parts of the Gulf of Lions, one of the coldest parts of the Mediterranean (Chevaldonné \& Lejeusne 2003). However, the seasonal variation of temperature in this area (maximum temperature range of $\sim 13^{\circ} \mathrm{C}$ ) seems to be compatible with all year round reproduction of $H$. margalefi, and to have been compatible with the all year round reproduction of $H$. speluncola until 1997 (see Chevaldonné \& Lejeusne 2003).

In mysid species, temperature has been shown to influence the reproductive cycle, physiology and growth. It has been documented to have significant effects on respiration, excretion, behaviour, egg size and growth of Hemimysis speluncola (Macquart-Moulin \& Patriti 1966, Gaudy \& Guérin 1979, Gaudy et al. 1980, Bourdillon \& Castelbon 1983, Wittmann 1984). In the present study, a negative relationship seems to exist between the mean sizes of Hemimysis margalefi's samples and water temperature. Similar observations were previously made on $H$. speluncola populations (Gaudy \& Guérin 1979). The highest water temperatures in early autumn coincide with the smallest mean sizes and, in contrast, the lowest temperatures in early spring coincide with the largest mean size. Such a pattern could be obtained if a massive increase in juveniles occurred in the population in autumn, implying a decrease in the sample mean size, but there is no evidence for this in any of the years surveyed. An alternative explanation could be that the larger size of individuals in spring is due to more favourable food conditions. However, productivity in caves and at their entrance in the Marseilles area only displays a peak in May-June (Fichez 1990b). This productivity peak is, therefore, too late to solely account for the larger sizes of spring individuals. In fact, considering the average life-span of $H$. margalefi ( 6 mo), a time-lag between the effects of water temperature on growth and the observed mean size of the population could explain this pattern. Indeed, adult individuals sampled during the period of warmest temperatures corresponded to the cohort that grew up during the coldest period; therefore, with a lower growth rate. For the same time span, cold seasons' cohorts present a smaller mean size than cohorts growing during warmer times of the year.

\section{Interactions between Hemimysis margalefi and Hemimysis speluncola}

Mysid species living in the coastal zone of temperate latitudes usually produce, at most, 3 cohorts per year (Mauchline 1980). Hemimysis speluncola and H. lamornae conform to such expectations, breeding 3 and 2 to 3 annual cohorts, respectively (Gaudy \& Guérin 1979, Mauchline 1980). H. margalefi does not seem to belong to this group of species since we found evidence of 4 annual cohorts. Mauchline (1980) reports that mysid species producing more than 3 cohorts a year usually live at latitudes lower than $40^{\circ}$. In the western Mediterranean, this corresponds to the southern parts of the basin, which harbours a comparatively higher proportion of thermophilic and/or subtropical species (Pérès \& Picard 1964). Based on experimental data as well as on observations of a recent regional warming-induced species replacement, a better tolerance to high temperature of $H$. margalefi compared to $H$. speluncola has been reported (Chevaldonné \& Lejeusne 2003). The present work, therefore, confirms that $H$. margalefi, with life-history traits typical of warm-water species, is definitely more thermophilic than its congener $H$. speluncola.

Such thermophilic traits in Hemimysis margalefi are certainly an advantage in the context of the regional warming of the NW Mediterranean. This is how Chevaldonné \& Lejeusne (2003) explain the recent shift in dominance from Hemimysis speluncola to $H$. margalefi in caves of this area, and the drastic reduction of $H$. speluncola populations, now facing risk of extinction. However, as pointed out by these authors, this temperature-related scenario, based on sub-lethal or sub-optimal conditions experienced by $H$. speluncola in 1997 and 1999, explains why the replacement took place at that particular time, but cannot entirely explain the processes by which the shift occurred. Processes such as interspecific competition are potential explanations for the mechanism of replacement. However, both species have been known to co-occur in several caves on a long-term basis (Chevaldonné \& Lejeusne 2003). Most likely, prior to the species shift, individuals of $H$. margalefi were diluted into millions of individuals of the previously dominant $H$. speluncola, which might have had a negative effect on the reproduction of $H$. margalefi due to the low probability of encounter between sexual partners. With the decline of one species, a social facilitation of the reproduction might have given $H$. margalefi a better chance to colonise the caves, as a result of an inverse density-dependent relationship or Allee effect (Courchamp et al. 1999, Stephens \& Sutherland 1999). Swarming is indeed reported to facilitate mating, in addition to playing a major role in antipredator vigilance, predator dilution, 
predator swamping, feeding facilitation, energy saving, reduction of genetic drift or inbreeding (Stephens \& Sutherland 1999, Ritz et al. 2001). The Allee effect might have maintained $H$. margalefi populations to low swarming densities when temperature conditions were still compatible with $H$. speluncola in the Marseilles area. The exceptional acute environmental conditions in 1997 and 1999 would have changed the dominance ratio to a point that allowed $H$. margalefi to establish large swarms in the caves.

The present work, for the first time, provides information on the biology and ecology of Hemimysis margalefi, particularly life-history traits (demographic structure and reproductive biology) in the context of warming of the NW Mediterranean waters. Such information is of great value to comprehend how such brooding species living in a highly fragmented habitat can maintain gene flow among populations. Such data can now be used as a background to conduct population genetic and molecular phylogeographic studies of Mediterranean Hemimysis.

Acknowledgements. We thank C. Marschal, R. Graille, F. Zuberer, B. de Ligondes and C. Jalong for assistance in collecting mysids, and J. G. Harmelin who kindly provided us with temperature data from the Riou archipelago. K. J. Wittmann, J. C. Sorbe, N. Boury-Esnault and 3 anonymous referees provided very helpful comments on the manuscript. C.L. benefited from doctoral awards distributed by the RAMOGE convention (A. Vatrican Award) and Grenoble University (Saint-Simon Award). This work was also supported in part by the Institut Français de la Biodiversité (IFB 00.406) and Total (contract no. 2002 003).

\section{LITERATURE CITED}

Alcaraz M, Riera T, Gili JM (1986) Hemimysis margalefi sp. nov. (Mysidacea) from a submarine cave of Mallorca Island, western Mediterranean. Crustaceana 50:199-203

Bhattacharya CG (1967) A simple method of resolution of a distribution into Gaussian components. Biometrics 23: 115-135

Bourdillon A, Castelbon C (1983) Influence des variations de température sur la géotaxie de deux espèces de mysidacés. J Exp Mar Biol Ecol 71:105-117

Chevaldonné P, Lejeusne C (2003) Regional warminginduced species shift in north-west Mediterranean marine caves. Ecol Lett 6:371-379

Courchamp F, Clutton-Brock T, Grenfell B (1999) Inverse density dependence and the Allee effect. Trends Ecol Evol 14:405-410

Fichez R (1990a) Decrease in allochthonous organic imputs in dark submarine caves, connection with lowering in benthic community richness. Hydrobiologia 207:61-69

Fichez R (1990b) Les pigments chlorophylliens: indices d'oligotrophie dans les grottes sous-marines. CR Acad Sci Paris Sér III 310:155-162

Fichez R (1991) Suspended particulate organic matter in a Mediterranean submarine cave. Mar Biol 108:167-174

Frontier S, Picho-Viale D (1991) Ecosystèmes: structure, fonctionnement, évolution. Masson, Paris
Gaudy R, Guérin JP (1979) Ecophysiologie comparée des mysidacés Hemimysis speluncola Ledoyer (cavernicole) et Leptomysis lingvura G. O. Sars (non cavernicole). Action de la température sur la croissance en élevage. J Exp Mar Biol Ecol 38:101-119

Gaudy R, Guérin JP, Pagano M (1980) Ecophysiologie comparée des mysidacés Hemimysis speluncola Ledoyer (cavernicole) et Leptomysis lingvura G. O. Sars (non cavernicole). Respiration et excrétion. J Exp Mar Biol Ecol 44: $29-46$

Giese AC (1959) Comparative physiology: annual reproductive cycles of marine invertebrates. Annu Rev Physiol 21: $547-576$

Harmelin JG (1997) Diversity of bryozoans in a Mediterranean sublittoral cave with bathyal-like conditions: role of dispersal processes and local factors. Mar Ecol Prog Ser 153:139-152

Harmelin JG, Vacelet J, Vasseur P (1985) Les grottes sousmarines obscures: un milieu extrême et un remarquable biotope refuge. Tethys 11:214-229

Harmelin JG, Boury-Esnault N, Fichez R, Vacelet J, Zibrowius $H$ (2003) Peuplements de la grotte sous-marine de l'île de Bagaud (parc national de Port-Cros, France, Méditerranée). Sci Rep Port-Cros Natl Park 19:117-134

Hart CW Jr, Manning RB, Iliffe TM (1985) The fauna of Atlantic marine caves: evidence of dispersal by sea floor spreading while maintaining ties to deep waters. Proc Biol Soc Wash 98:288-292

Ketelaars HAM, Lambregts-van de Clundert FE, Carpentier CJ, Wagenvoort AJ, Hoogenboezem W (1999) Ecological effects of the mass occurrence of the Ponto-Caspian invader, Hemimysis anomala G.O. Sars, 1907 (Crustacea: Mysidacea), in a freshwater storage reservoir in the Netherlands, with notes on its autecology and new records. Hydrobiologia 394:233-248

Ledoyer M (1963) Hemimysis speluncola n. sp. mysidacé nouvelle des grottes sous-marines obscures. Rec Trav St Mar Endoume 30:77-81

Ledoyer M (1989) Les mysidacés (Crustacea) des grottes sousmarines obscures de Méditerranée nord-occidentale et du proche Atlantique (Portugal et Madère). Mar Nat 2:39-62

Lejeusne C (2002) Structures démographique et génétique de populations de mysidacés cavernicoles de la région marseillaise dans un contexte de réchauffement global. Rapport de DEA, Centre d'Océanologie de Marseille-Université de la Méditerranée, Marseille

Macdonald PDM, Green PEJ (1988) Users guide to program MIX 2.3: an interactive program for fitting mixtures of distributions. Technical notes on release 2.3. Ichtus Data Systems, Hamilton, Ontario

Macquart-Moulin C, Patriti G (1966) Remarque sur la biologie d'Hemimysis speluncola, Ledoyer, mysidacé sciaphile des grottes sous-marines obscures de la région de Marseille. Rec Trav St Mar Endoume 40:253-258

Mauchline J (1971) Seasonal occurrence of mysids (Crustacea) and evidence of social behaviour. J Mar Biol Assoc UK 51:809-825

Mauchline J (1973) The broods of British Mysidacea (Crustacea). J Mar Biol Assoc UK 53:801-817

Mauchline J (1980) The biology of mysids and euphausiids. Adv Mar Biol 18:1-681

Oh CW, Hartnoll RG (2004) Reproductive biology of the common shrimp Crangon crangon (Decapoda: Crangonidae) in the central Irish Sea. Mar Biol 144:303-316

Passelaigue F, Bourdillon A (1986) Distribution and circadian migrations of the cavernicolous mysid Hemimysis speluncola Ledoyer. Stygologia 2:112-118 
Pérès JM, Picard J (1964) Nouveau manuel de bionomie benthique de la mer Méditerranée. Rec Trav St Mar Endoume 31:5-137

Ribes M, Coma R, Zabala M, Gili JM (1996) Small-scale spatial heterogeneity and seasonal variation in a population of a cave-dwelling Mediterranean mysid. J Plankton Res 18:659-671

Ritz DA, Foster EG, Swadling KM (2001) Benefits of swarming: mysids in larger swarms save energy. J Mar Biol Assoc UK 81:543-544

San Vicente C, Sorbe JC (1993) Biologie du mysidacé suprabenthique Schistomysis parkeri Norman, 1892 dans la zone sud du Golfe de Gascogne (plage d'Hendaye). Crustaceana 65:222-252

Scherrer B (1984) Biostatistique. Gaëtan Morin, Montreal

StatSoft (1998) STATISTICA pour Windows. StatSoft France, Maisons-Alfort

Stephens PA, Sutherland WJ (1999) Consequences of the Allee effect for behaviour, ecology and conservation. Trends Ecol Evol 14:401-405

Editorial responsibility: Otto Kinne (Editor-in-Chief), Oldendorf/Luhe, Germany
Vacelet J, Boury-Esnault N (1995) Carnivorous sponges. Nature 373:333-335

Vacelet J, Boury-Esnault N (1996) A new species of carnivorous sponge (Demospongiae: Cladorhizidae) from a Mediterranean cave. Bull Inst R Sci Nat Belg, Biol 66: $109-115$

Vacelet J, Boury-Esnault N, Harmelin JG (1994) Hexactinellid Cave, a unique deep-sea habitat in the SCUBA zone. Deep-Sea Res I 41:965-973

Wittmann KJ (1981) On the breeding biology and physiology of marsupial development in Mediterranean Leptomysis (Mysidacea: Crustacea) with special reference to the effects of temperature and egg size. J Exp Mar Biol Ecol 53:261-279

Wittmann KJ (1984) Ecophysiology of marsupial development and reproduction in Mysidacea (Crustacea). Oceanogr Mar Biol Annu Rev 22:393-428

Wittmann KJ (2001) Centennial changes in the near-shore mysid fauna of the gulf of Naples (Mediterranean Sea), with description of Heteromysis riedli sp. n. (Crustacea, Mysidacea). PSZN I: Mar Ecol 22:85-109

Submitted: June 22, 2004; Accepted: September 2, 2004 Proofs received from author(s): January 26, 2005 